\title{
Impact of Job Stress on Job Performance and Turnover Intention Among Employees in Hospitality Industry in Ghana
}

\author{
Kwame Asare Duffour \\ duffour24@gmail.com \\ School of Business Administration, \\ Zhejiang Gongshang University, Hangzhou, China \\ Patrick Kweku Gbolonyo \\ patrickgbolonyo@yahoo.com \\ School of Statistics and Mathematics, \\ Zhejiang Gongshang University, Hangzhou, China \\ Ting Chen \\ gaby@mail.zjgsu.edu.cn \\ School of Business Administration, \\ Zhejiang Gongshang University, Hangzhou, China \\ https://doi.org/10.51137/ijarbm.2021.2.2.4
}

\begin{abstract}
Work stress and uncivil behaviors have their side effects socially, physically, and mentally on employees and thus hinders the performance and growth of the individual and the organization as a whole. Nevertheless, over the past years, there have been numerous theoretical and practical studies devoted to stress reduction and how it affects job performance and turnover intention. The present study objective is to examine the influence of job stress on employee job performance and turnover intention in the Ghanaian hospitality industry. We tested the research hypothesis using a total of 367 working adults and completed the questionnaire on the level of job stress impact on workplace incivility, job performance, and turnover intention. Results indicated that emotional exhaustion (EE) was found to have a positive significant relationship to job performance (JP). Job Stress (JS) was found to have a significant negative relationship to job performance but a positive relationship to turnover intention and workplace incivility. Also, the relationship between workplace incivility (WI) and Turnover Intention ( $\mathrm{TI})$ has shown to be positive and significant whiles workplace incivility did not have any significant relationship with job performance. Managers should set informal standards for ideal workplace behaviors and encourage employees to choose ways to cope with work stress to improve job performance. This study provides novel insights for job stress and developing effective employee strategies in curtailing workplace incivility and turnover intention.
\end{abstract}

Keywords - Job Stress, Job Performance, Turnover Intention, Workplace Incivility, Emotional Exhaustion. 


\section{Introduction}

The nature of work in running todays' organization has gone through various changes within the last century and affected every aspect of professionals around the globe. Over the past few decades, job stress has materialized as an increasing problem in an organization. It is costly and a setback in the western part of the world, specifically in the United States (Siu et al., 2003). Stress is a demanding obstacle that influences the effectiveness, efficiency, and performance of an organization. The sources of stress originate from various forms of business lifestyles. In conservation of resource theory (COR), job stress can be described as the feeling of stress at the workplace. The COR theory explains that employees experience stress when: they have the fear of losing resources on hand; deprived of their resources; or with required resources on hand, they are not able to complete their task in accomplishing their stated goals (Akgunduz, 2014). Stress is when an individual is faced with choices on how your body will react to demand or threat which is uncertain and vital. Stress founding researcher Hans Selye, 1936 defines stress as the drive, mental or emotional strain exerted on an individual and who repel these forces in a strive to ratify its true state. In 1956, he came out with the view that stress is not necessarily something negative, but it depends on how the individual handles it.

Organizations need to achieve their goals in a competitive industry and this makes employers demand job performance increases for employees (Akgunduz, 2014). Smith and Goddard (2002) define high job performance as the management of human capital, management of time, and being costefficient in utilizing organizational resources to accomplish the task on time. Employees' high job performance gives them a sense of satisfaction, increase in skills, self-confidence, and job involvement in the organization (Fay \& Sonnentag, 2002). In other, for employees to perform at their maximum performance, it will depend on the working environment and the capability of the employee. Therefore, the expected level of performance from employees will need careful recruitment for the specific employee to be on duty to perform (Van Yperen \& Hagedoorn, 2003). This study seeks to examine the impact of job stress on employee performance and turnover intention among employees in the hospitality industry in Ghana. To the best of the knowledge of the researcher, the present study will contribute to filling the gap that exists in research on job stress and its impact on employee job performance and turnover intention in the context of Ghana. The introduction of emotional exhaustion as the moderator also helps in explaining the link between workplace incivility and job performance.

\section{Theoretical Review}

Workplace incivility refers to "low-intensity behavior designed to hide the purpose of injury and violate mutually respectful work standards (Andersson \& Pearson, 1999). Also, employee turnover refers to the phenomenon of employees voluntarily leaving the organization (Shaw et al., 2005). Job performance describes the activities or procedures related to the formal duties, tasks, and responsibilities required for the job (Carpini et al., 2017). In this Impact of Job Stress on Job Performance and Turnover Intention Among Employees in Hospitality Industry in Ghana 
study, cognitive appraisal theory invented by Richard Lazarus and colleagues (Folkman \& Moskowitz, 2004) to elaborate on coping responses to stressful situations was adopted. Appraisals are inversely related to dimensions in a way that their explanation of features of events combine to cause particular emotions, while dimensions are original genes of emotions. How an individual evaluates an encounter with the environment in which he/she lives concerning his /her well-being is known as cognitive appraisal. In primary appraisal, the person evaluates whether he or she has anything at stake in this encounter. In secondary appraisal, the person evaluates if there is anything to outwit or prevent harm or to improve the prospects for benefit. Primary and secondary appraisals link up to determine whether the personenvironment transaction is seen as important for well-being, and if so, whether it is primarily threatening (containing the possibility of harm or loss), or challenging (holding the possibility of mastery or benefit). Folkman \& Lazarus (1985) defined coping as the dynamic behavior of an individual and his/her management of inner and outer demands that are appraised and over his/her resources on hand. In real-life events, how a person experiences something that has occurred will depend on his/her instinct and conscience of what has happened. When there is no psychological arousal concerning the happened event, the person will react positively or negatively to what happened. After these occurrences, the individual starts to develop some thoughts on the cause of the event. A sequence of cognitive appraisal theory is realized in this scenario. There are particularly two well-known functions of coping, First, controlling or managing stressful emotions (emotions-focused coping). The second function has to do with changing the environment concerning the discomfort (problem-focused coping). Previous research results showed that both coping mainly involve both functions. Why Appraisal Theory: A stressed person feels emotionally upset and uneasy in the environment he/she has an attachment to. Appraisal theory will help to understand the theoretical picture for examining emotional differentiation (C. A. Smith et al., 2014). As in most current approaches to emotion (e.g., Frijda (1987)), emotions are viewed as largely adaptive responses to the perceived environmental demands confronting an individual, with emotion viewed, in part, as a signal system that serves important adaptational functions (Simon, 1967). Different emotions are generated by situations that have different types of adaptational priorities.

\subsection{Hypothesis Development and Conceptual Framework}

\subsubsection{Job Stress and Workplace Incivility}

Some of the elements responsible and dominant in creating stress among employees in Ghana are job content and demands, role conflict, and low salaries. These elements were used in figure 1 to elaborate on the causes and definition of job stress. Job content and demands refer to all aspects of a job, including the cost of the staff performing the duties required for the job (Bakker \& Demerouti, 2007). Role conflict arises when the role requirements of an employee are contradictory to the other (Settles et al., 2002). Lastly, when the effort of employees is not rewarded to expectation and satisfaction, this creates stress among them and results in workplace incivility and job performance. Bacharach, Bamberger, and Sonnenstuhl (2002) found that Impact of Job Stress on Job Performance and Turnover Intention Among Employees in 
work-related stress leads to higher levels of employees who drink alcohol in the workplace. Employees are forced to drink to cope with stressful working conditions. Bruk-Lee and Spector (2006) reported that there was a positive correlation between social stressors and counterproductive workplace behavior (CWB), and more people interacting with their peers under pressure than those who experienced a healthy interaction. Bowling and Eschleman (2010) prove that role-related stressors, organizational limitations, and interpersonal conflicts are related to CWB and that different types of stressors in the workplace have similar negative consequences. In addition to many studies citing a positive correlation between stress and workplace incivility, $\mathrm{Lau}, \mathrm{Au}$, and Ho (2003) published a meta-analysis report indicating that stress in the workplace was positively correlated with violence, substance abuse, absenteeism, and robbery. Our study correlates the relationship between stress and uncivilization with instances of an uncivilized work environment caused by uncivilized work, as supported by Penney and Spector (2005). Therefore, the following hypothesis is proposed

H1: Job stress is positively related to workplace incivility.

\subsubsection{Workplace Incivility and Job Performance}

Workplace incivility impacts can affect the ability of current employees to perform their tasks in various ways (Pearson \& Porath, 2005). First, workers exposed to rigor in the workplace may not be able to perform all the tasks required for the job within a relatively narrow range of cognitive options. Rude behavior in the workplace can cause subjective emotional reactions in employees and lead to cognitive decline (Griffin \& Clark, 2014; Sakurai \& Jex, 2012). Victims can have various forms of selective prosecution (Judge et al. 2001). For example, the ability of employees to learn and understand several daily tasks simultaneously is limited by negative emotional reactions (T. Foulk et al., 2016). Their ability to remember and use knowledge in the workplace will also be affected (Nicholson \& Griffin, 2014). Therefore, workers facing rudeness at work will reduce their chances of getting the job done at work. The task-oriented cognitive resources of employees are distracted by rude behavior (T. A. Foulk et al., 2018; Porath \& Erez, 2007). According to Affective Events Theory (AET), victims can recall tense events, assess the legitimacy of peer behavior, and consider different responses to rude behavior (Porath et al., 2008; Sakurai \& Jex, 2012). Ciarocco, Vohs, and Baumeister (2010) believe that stressful emotions and events can promote the active exploration of thoughts and emotions. While there are some benefits, it can destroy employee-focused cognitive resources and reduce their ability to perform this role. Based on the preceding discussion, the following hypothesis is proposed

H2: Workplace incivility is positively related to job performance.

\subsubsection{Workplace Incivility and Turnover Intention}

The employee's decision to leave the organization is costly to both the individual and the organization (Lee et al., 2004). The calculation of personnel costs usually considers three main factors, including redundancy, replacement, and training costs (Cascio, 1984). Starr et al. (2005) pointed out that the average employee turnover rate in the United States is about 15\%; however, this varies from industry to industry. Abuse is a daily phenomenon, 
many organizations are often unaware of its damaging effects, and most executives are reluctant to deal with it. Pearson and Porath (2005) found that targets with disabilities, witnesses, and other participants reported that their actions would undermine the organizational value and waste organizational resources. Due to their experience with disability, employees noticed a decrease in labor, working hours, and job performance. Some employees even resigned due to the influence of this subtle form of deviation. There is evidence that organizations that promote a relationship-oriented culture experience more voluntary service than those that do not (Sheridan, 1992). Hansen (1993) found evidence that victims of workplace abuse may consider leaving the organization voluntarily, whether by relocating the headquarters or voluntarily leaving the company. As mentioned above, leaving a job due to a lot of activities can lead to burnout, which can lead to a change of intention. In other words, doing nothing leads to burnout, which in turn leads to sales intent. Based on the theoretical rationale discussed above and previous findings on the subject, we propose the following hypothesis

H3: Workplace incivility is positively related to turnover intention.

\subsubsection{Emotional Exhaustion Impact on Workplace Incivility and Job Performance}

In many cases, the resources available to people are limited and environmental factors such as uncivilized work (uncivilized colleagues, clients, managers) quickly deplete these resources. When these resources fall to a certain level, these people are exhausted (Neveu, 2007). The COR theory also suggests the loss of physical, emotional, and cognitive resources due to the uncivil behavior of colleagues. In addition to the mechanisms of resource availability, the loss of resources due to the uncivil behavior of colleagues seems to depend on human reaction. The reduction of resources is an important aspect of emotional distress (Neveu, 2007). Like COR theory, AET helps explain how rude behavior from colleagues affects emotional fatigue in frontline workers. In particular, workplace accidents are believed to be one of the main causes of employee emotional reactions. The work environment (i.e., uncivilized colleagues) is not only the emotional state of the staff (i.e., fatigue, anxiety, misery, anger) but also their behavioral reactions (emotional work, quality of service, organizational commitment), (Weiss \& Cropanzano, 1996). Given the relationship between stress, emotional exhaustion, and job performance in the Koeske and Koeske (1993), the current study highlights the negative effects of emotional fatigue on the performance of front-line staff. This is confirmed by the COR theory, which shows that people always suffer negative psychological consequences that cause emotional fatigue in the face of the demands of social interaction and the threat of loss of resources (Hobfoll, 2001). Therefore, the following assumptions are made

H4: Emotional exhaustion moderates the relationship between workplace incivility and job performance.

\subsubsection{Job Stress and Job Performance}

Stress is also related to "demand" and "resources". Demands are the expectations, situations, and circumstances of an organization, and resources are used to meet the demands. If resources are sufficient to meet demand, stress levels are minimized. Different employees appreciate the workload 
differently. Some are convenient to handle at work, while others are difficult to manage. If the demands of a person's role are opposite, it causes role conflict. This is a critical situation because meeting the demands of one role makes it difficult to meet the demands of another role. When an employee believes their efforts will not bear fruit this causes stress between them and therefore reduces their performance. By paying more, companies can recruit talented and motivated employees, which is one of the highest operating costs for a business. The effects of stressors, such as role conflicts and role ambiguity, have been shown to negatively affect the ability of employees to perform their tasks (Jackson \& Schuler, 1985). In short, as Jex (1998) concludes, increased stress reduces work performance. Therefore, stress at work is believed to have a direct negative impact on work performance. Based on the theoretical arguments discussed above, we propose the following hypothesis

H5: Job stress has a direct positive influence on job performance.

\subsubsection{Job Stress and Turnover Intention}

High stress at work for experienced employees is always unhealthy, less motivated and less predictable, less determined to stay in Arshadi and Damiri (2013). Tett and Meyer (1993) argued that the intention to turn was a deliberate bias to reduce productivity and an intention to leave the job (Applebaum et al., 2010). A previous researcher found that higher stress levels increase the intention to change (Applebaum et al., 2010; Chen et al., 2010). Noor and Maad (2009) have confirmed links between stress and intentions for change. Furthermore, Arshadi and Damiri (2013) found that stress at work is strongly associated to rotate. Extreme stress at work negatively affects an individual's performance and also leads to undesirable behavior and attitude outcomes at work (Barling et al., 2005). High work-related stress provokes a rotational response (Sawyerr et al., 2009). Feeling stressed, such as emotional exhaustion, not only lowers the level of job satisfaction, it can also increase employees' intention to quit. Therefore, employees who experience high levels of stress at work are expected to leave the organization more frequently (Shih-Tse Wang, 2014). Therefore, we propose the following hypothesis:

H6: Job stress has a direct positive influence on turnover intention. 


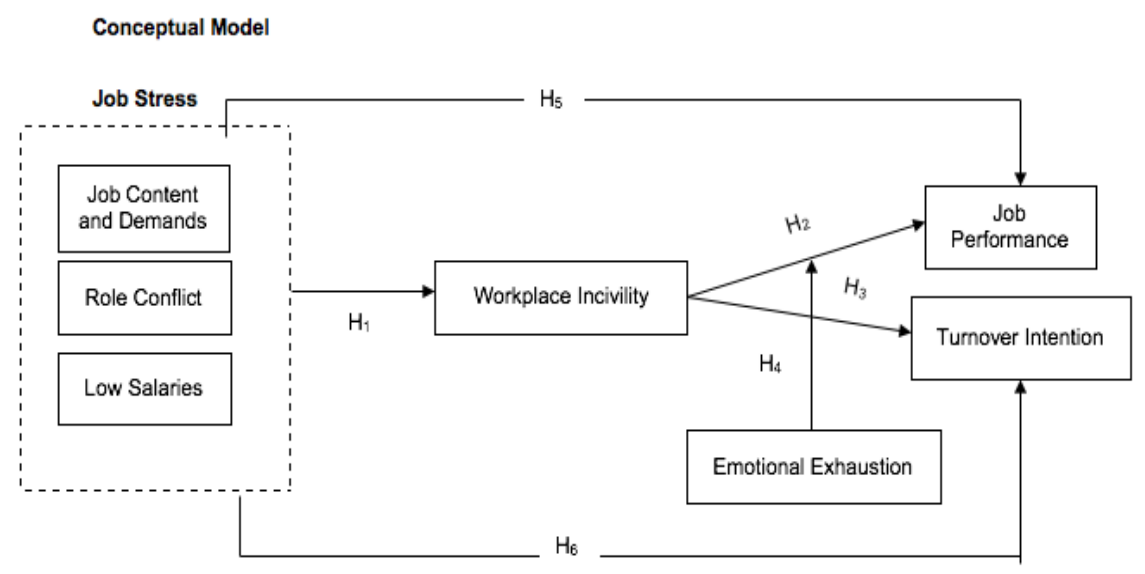

Figure 1: Conceptual Model

\section{Methodology}

\subsection{Participants, Procedure, and Measurement}

The study adopted a quantitative research approach and respondents were selected mainly from food and beverage service, event planning, and travel and tourism in Ghana. This study participants were employees of these service providers in the hospitality industry. A total of 500 employees were randomly contacted to participate in the survey, of which 367 participated representing a $73.4 \%$ response rate. A non-probability sampling technique (convenience sampling) was adopted for this study. The main data collection instrument used for the study is questionnaire administration with the selected sample population. The researchers used a 7-point Likert scale from strongly disagree, disagree, somewhat disagree, neutral, somewhat agree, agree, and strongly agree, to collect responses from the participants. The main data collection instruments used for the study are primary data and questionnaire administration which were subsequently analyzed via SPSS version 26.0 to assess the demographic information of respondents. Smart PLS 3.2.9 was employed to assess the measurement and the structural model (Henseler et al., 2015) using Partial Least Square. Job stress measurement items were adopted from Firth, et al. (2004). Workplace incivility was jointly composed of items taken from Cortina et al. (2001). Respondents were asked the rate of experiences of uncivil behaviors from coworkers. The emotional intention to leave the organization was adopted from Alniaçik et al. (2013), and Maslach and Jackson (1981). Job performance was measured using five items adapted from Liao and Chuang (2004) while the turnover intention was adapted from Netemeyer et al. (1997) and Brashear et al. (2003). 


\section{Data Analysis}

The demographic characteristics of the respondents per the study are shown in Table 1. The study made use of 367 respondents of which the majority $(58.3 \%)$ were females. Most of the respondents were between the ages of $31-40$ years $(50.1 \%)$ followed by $41-50$ years $(32.4 \%)$. With regards to their level of education, a greater number $(80.4 \%)$ of them were those with bachelor's degrees and diplomas. As to which hospitality industry do each respondent work in, a majority (37.9\%) of them worked at the food and beverages service followed by the event planning industry (34.3\%).

Table 1: Statistics of Demographic Variables $(N=367)$

\begin{tabular}{llll}
\hline Variables & $\begin{array}{l}\text { Measurement } \\
\text { Items }\end{array}$ & Frequency & $\begin{array}{l}\text { Percentage } \\
(\%)\end{array}$ \\
\hline Gender & Male & 153 & 41.4 \\
& Female & 214 & 58.3 \\
Age & 18-30 years & 37 & 10.1 \\
& $31-40$ years & 184 & 50.1 \\
& $41-50$ years & 119 & 32.4 \\
Educational Level & 51 years and above & 27 & 7.4 \\
& Diploma & 120 & 32.7 \\
& Bachelor & 175 & 47.7 \\
Which Hospitality & Postgraduate & 25 & 6.8 \\
Industry do you & Others & 47 & 12.8 \\
work in? & Food and Beverages & 139 & 37.9 \\
& Service & & \\
& Event Planning & 126 & 34.3 \\
& Travel and Tourism & 95 & 25.9 \\
\hline
\end{tabular}

Note: $N$ = Sample Size

The study further employed SmartPLS version 3.2.9 to evaluate the composite reliability, internal consistency as well as discriminant validity of the measurement items (Table 2). Also, the result found that all the Cronbach's Alpha (CA) and Composite Reliability (CR) values of each construct surpass the threshold value of 0.70 suggesting constructs reliability and validity. At the same time, the Average Variance Extracted (AVE) values for each construct were significantly higher than the 0.50 threshold recommended by Hair et al. (2011). 
Table 2: Constructs Reliability and Validity

\begin{tabular}{|c|c|c|c|c|c|}
\hline Construct & Loadings & CR & CA & AVE & Significance \\
\hline $\begin{array}{l}\text { Emotional } \\
\text { Exhaustion (EE) }\end{array}$ & & 0.897 & 0.847 & 0.685 & $\overline{k \star \star}$ \\
\hline EE & 0.779 & & & & \\
\hline EE2 & 0.839 & & & & \\
\hline EE3 & 0.868 & & & & \\
\hline EE4 & 0.822 & & & & \\
\hline $\begin{array}{l}\text { Job } \\
\text { Performance } \\
\text { (JP) }\end{array}$ & & 0.898 & 0.848 & 0.687 & $* \star *$ \\
\hline JP1 & 0.843 & & & & \\
\hline JP2 & 0.846 & & & & \\
\hline JP3 & 0.818 & & & & \\
\hline JP4 & 0.807 & & & & \\
\hline Job Stress (JS) & & 0.922 & 0.889 & 0.748 & $* * *$ \\
\hline JS1 & 0.845 & & & & \\
\hline JS2 & 0.849 & & & & \\
\hline JS3 & 0.881 & & & & \\
\hline JS4 & 0.884 & & & & \\
\hline $\begin{array}{l}\text { Turnover } \\
\text { Intention (TI) }\end{array}$ & & 0.890 & 0.835 & 0.669 & $* * *$ \\
\hline TI1 & 0.810 & & & & \\
\hline $\mathrm{Tl} 2$ & 0.813 & & & & \\
\hline $\mathrm{Tl} 3$ & 0.817 & & & & \\
\hline TI4 & 0.831 & & & & \\
\hline $\begin{array}{l}\text { Workplace } \\
\text { Incivility (WI) }\end{array}$ & & 0.917 & 0.879 & 0.733 & $* * *$ \\
\hline WI1 & 0.835 & & & & \\
\hline WI2 & 0.863 & & & & \\
\hline WI3 & 0.856 & & & & \\
\hline WI4 & 0.871 & & & & \\
\hline
\end{tabular}

Table 3 displays the result of another form of discriminant validity assessment using heterotrait-monotrait ratio (HTMT) to measure the strength of correlation among the constructs (Henseler et al., 2015). According to Henseler et al. (2015), the heterotrait-monotrait ratio (HTMT) values have to be less than 0.90 for good discriminant validity. As per the result in Table 4, the HTMT ratio values were significantly lower than the maximum restrictive benchmark of 0.90 evidencing discriminant validity of constructs. 
Table 3: Heterotrait-Monotrait ratio (HTMT)

\begin{tabular}{clllll}
\hline Constructs & EE & JP & JS & TI & WI \\
\hline EE & & & & & \\
JP & 0.540 & & & \\
JS & 0.064 & 0.071 & & \\
TI & 0.080 & 0.062 & 0.442 & \\
WI & 0.112 & 0.105 & 0.422 & 0.340 & \\
\hline
\end{tabular}

Note: $E E=$ Emotional Exhaustion, $J P=$ Job Performance, $J S=$ Job Stress, $T I=$ Turnover Intention, $W I=$ Workplace Incivility.

We further determined the significance of the path coefficients as well as the indirect effect of the constructs via the bootstrap re-sampling function method (Hair et al., 2011) integrated into the SmartPLS to examine the hypothesized relationship (Henseler et al., 2015). The constructs' path coefficient is made up of standardized values ranging from -1 to +1 . The closer the estimated path coefficients are to 1 and 0 , the stronger and weaker the estimated relationship respectively, according to the standardized values. The path coefficient for the structural model displaying the direct and total effect of the hypothesis is shown in Table 4. The result revealed four (4) out of the seven (7) hypotheses tested were statistically significant. For example, Emotional Exhaustion (EE) was found to behave positive significant relationship to Job Performance $(\mathrm{JP})(\beta=0.832$, $\mathrm{t}$-value $=32.557, \mathrm{p}$-value $=$ 0.001 ) while Job Stress (JS) was found to have significant negative and positive relationship to Turnover Intention (TI) $(\beta=-0.411$, t-value $=6.715, p$ value $=0.001)$ and Workplace Incivility $(\mathrm{WI})(\beta=0.387$, $\mathrm{t}$-value $=7.010, \mathrm{p}$ value $=0.001)$ respectively. At the same time, the relationship between Workplace Incivility $(\mathrm{WI})$ and Turnover Intention (TI) has shown to be positive and significant $(\beta=0.140$, t-value $=2.510, p$-value $=0.012)$. However, Job Stress $(J S)(\beta=-0.019$, t-value $=0.702, p$-value $=0.483)$ and Workplace Incivility $(\mathrm{WI})(\beta=-0.004$, $\mathrm{t}$-value $=0.053$, $\mathrm{p}$-value $=0.958)$ did not have any significant relationship on Job Performance (JP) respectively. In conclusion, Emotional Exhaustion (EE) was found not to moderate the relationship between Workplace Incivility (WI) and Job Performance (JP) $(\beta=0.038$, t-value $=0.712$, p-value $=0.477$ ). 
Table 4: Structural Model Constructs Path Coefficients

\begin{tabular}{|c|c|c|c|c|c|}
\hline Construct Effect & $\beta$ & SD & $\mathbf{t}$ & $\mathbf{p}$ & Conclusion \\
\hline$E E->J P$ & 0.832 & 0.026 & 32.557 & $0.001^{* \star *}$ & Significant and Supported \\
\hline JS -> JP & -0.019 & 0.027 & 0.702 & 0.483 & th and \\
\hline $\begin{array}{l}\mathrm{JS} \rightarrow \mathrm{TI} \\
\mathrm{JS} \rightarrow \mathrm{WI}\end{array}$ & $\begin{array}{l}-0.411 \\
0.387\end{array}$ & $\begin{array}{l}0.061 \\
0.054\end{array}$ & $\begin{array}{l}6.715 \\
7.010\end{array}$ & $\begin{array}{l}0.001^{* * *} \\
0.001^{* * *}\end{array}$ & $\begin{array}{l}\text { Significant and Supported } \\
\text { Significant and Supported }\end{array}$ \\
\hline $\begin{array}{l}\text { Moderating Effect } \\
\text { (EE) } \rightarrow \text { JP }\end{array}$ & 0.038 & 0.048 & 0.712 & 0.477 & Not Supported \\
\hline WI $->$ JP & -0.004 & 0.033 & 0.053 & 0.958 & Not Supported \\
\hline $\mathrm{WI}->\mathrm{TI}$ & 0.140 & 0.057 & 2.510 & $0.012^{* *}$ & Significant and Supported \\
\hline
\end{tabular}

Table 5 summarizes the assessed result for the mediation role of Workplace Incivility (WI) to Job Performance (JP) and Turnover Intention (TI). From the result, it was revealed that the relationship between Job Stress (JS) and Turnover Intention (TI) was mediated by Workplace Incivility (WI) ( $\beta$ $=0.054$, t-value $=2.283, \mathrm{p}$-value $=0.023$.

Table 5: Mediation Role of Workplace Incivility (Specific Indirect effect)

\begin{tabular}{lcccc}
\hline Constructs Effect & $\boldsymbol{\beta}$ & SD & $\mathbf{t}$ & $\mathbf{p}$ \\
\hline $\mathrm{JS}->\mathrm{WI}->\mathrm{JP}$ & -0.001 & 0.013 & 0.052 & 0.959 \\
$\mathrm{JS} \rightarrow \mathrm{WI}->\mathrm{TI}$ & 0.054 & 0.024 & 2.283 & $0.023^{\star \star}$ \\
\hline
\end{tabular}

Note: ${ }^{* *} p$-values $<0.05, J P=$ Job Performance, $J S=$ Job Stress, $T I=$ Turnover $I n-$ tention, $W I=$ Workplace Incivility.

Additionally, we evaluate the coefficient of determination via the R-Square adjusted to assess the amount of variation in the dependent constructs (such as Job Performance (JP), Turnover Intention (TI), and Workplace Incivility $(\mathrm{WI})$ ) that is explained by the independent construct. As shown in Table 6 , the adjusted R-Square values of $0.704(p$-value $=0.001)$ revealed that Job Stress (JS), Workplace (WI), and Emotional Exhaustion (EE) jointly explained about $70.4 \%$ of the variability in the dependent variable, Job Performance (JP). Similarly, Job Stress (JS) and Workplace Incivility (WI) jointly explain about $23.6 \%$ (adjusted R-Square $=0.236$, $\mathrm{p}$-value $=0.001$ ) of the variability in the dependent variable, Turnover Intention (TI) even though Job Stress (JS) explains about $15 \%$ (adjusted R-Square $=0.150, p$-value $=0.001)$ of the variance in the dependent variable Workplace Incivility (WI). 
Table 6: Adjusted R-Square Statistics

\begin{tabular}{ccccc}
\hline Constructs Effect & $\mathrm{R}^{2}$ & $\mathrm{SD}$ & $\mathrm{t}$ & $\mathrm{p}$ \\
\hline Job Performance & 0.704 & 0.036 & 19.442 & $0.001^{* * *}$ \\
Turnover Intention & 0.236 & 0.057 & 4.025 & $0.001^{* * *}$ \\
Workplace Incivility & 0.150 & 0.042 & 3.404 & $0.001^{* * *}$ \\
Note: ${ }^{* \star *} p$-values $<0.01$ & & & &
\end{tabular}

As per this study, we assess the effect size via the f-square statistics to determine the structural model's predictive strength (Table 7). The effect size was evaluated using Cohen's (1992) guideline where the f-square values less than 0.02 were considered as no effect, between 0.02 and 0.14 as a weak or small effect, between 0.15 and 0.34 as the medium effect, and 0.35 above as large effect. From Table 7, Emotional Exhaustion (EE) was found to have a significant large effect on Job Performance (JB) while Job Stress (JS) has been shown to have a significant medium effect on Turnover Intention (TI) and Workplace Incivility (WI). However, there was no significant effect of Job Stress (JS) and Workplace Incivility (WI) on Job Performance (JP) besides Workplace Incivility (WI) having a significant small effect on Turnover Intention (TI). Again, there is no significant moderating effect of Emotional Exhaustion (EE) on Job Performance (JP).

Table 7: F-Square Statistics (Effect Size)

\begin{tabular}{ll}
\hline Constructs Effect & Effect Size (F-Square) \\
\hline Emotional Exhaustion -> Job Performance & $2.188^{* * *}$ \\
Job Stress -> Job Performance & $0.003^{*}$ \\
Job Stress -> Turnover Intention & $0.196^{* * *}$ \\
Job Stress -> Workplace Incivility & $0.183^{* * *}$ \\
Moderating Effect (EE) -> Job Performance & $0.005^{\star}$ \\
Workplace Incivility -> Job Performance & $0.003^{\star}$ \\
Workplace Incivility -> Turnover Intention & $0.026^{* *}$
\end{tabular}

Note: Less than $0.02^{*}=$ no effect, from 0.02 to $0.14^{* *}=$ small/weak effect, 0.15 to $0.34^{* \star *}=$ medium effect, $0.35^{* \star *}$ and above = large effect 


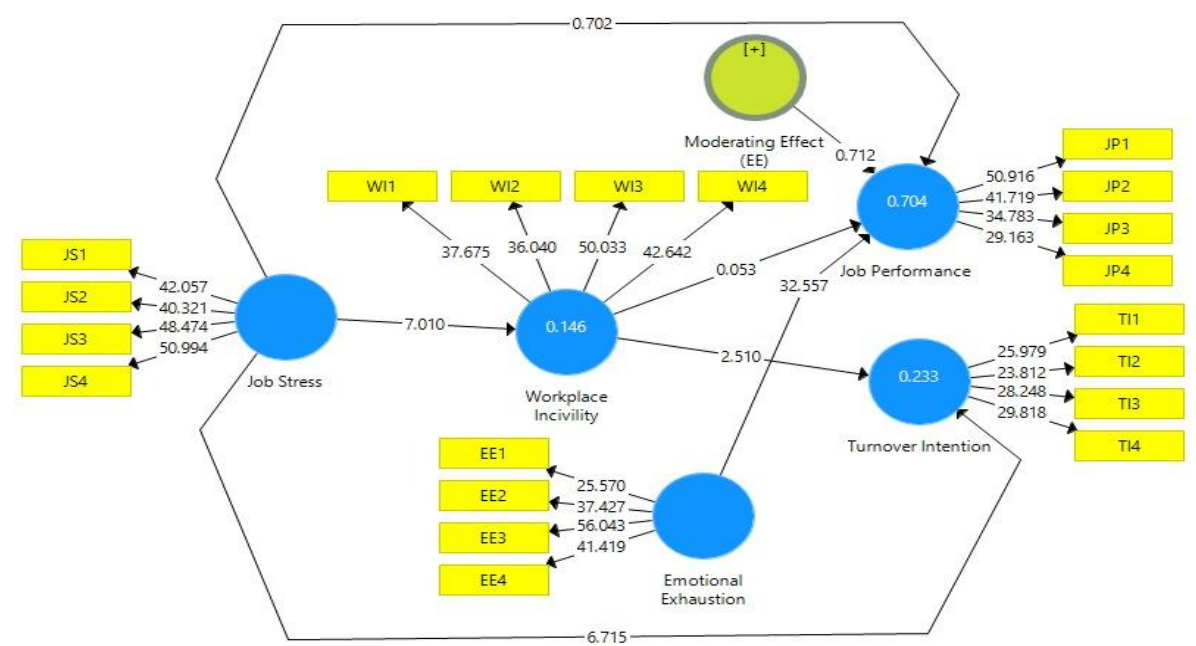

Figure 2: Structural model of Job Stress on job performance and turnover intention

\section{$5 \quad$ Discussion and Implications}

The study investigation tested a model of job stress on job performance and turnover intention among employees in the hospitality industry in Ghana. Results indicated clear support for the model as demonstrated in Figure 1: job stress was positively associated with workplace incivility (H1). Also, workplace incivility was negatively associated with job performance $(H 2)$ whiles it was positively associated with turnover intention (H3). Furthermore, the moderation effect of emotional exhaustion on workplace incivility and job performance was not significant (H4). In addition, job stress was negatively associated with job performance (H5) but was positively associated with turnover intention (H6). The findings of the study were not influenced by common method variance which is a serious limitation in research on social and management sciences. According to Nunnally and Bernstein (1994) and Fornell and Larcker (1981), the Composite Reliability and Cronbach's Alpha values have to be more than 0.70 to guarantee the reliability and validity of the constructs. The loading for all the measurement items was significantly higher than the 0.708 benchmarks according to Hair et al. (2011). Table 8 displays the summary of the tested hypotheses base on the research findings. 
Table 8: Status of the Hypotheses base on the research findings

\begin{tabular}{clc}
\hline No. & Research Hypotheses & $\begin{array}{l}\text { Research } \\
\text { Status }\end{array}$ \\
\hline H1 & $\begin{array}{l}\text { Job stress is positively related to workplace } \\
\text { incivility. }\end{array}$ & Accepted \\
H2 & $\begin{array}{l}\text { Workplace incivility is positively related to job perfor- } \\
\text { mance. }\end{array}$ & Rejected \\
H3 & $\begin{array}{l}\text { Workplace incivility is positively related to } \\
\text { turnover intention. }\end{array}$ & Accepted \\
H4 & $\begin{array}{l}\text { Emotional exhaustion moderates the } \\
\text { relationship between workplace incivility and job } \\
\text { performance. }\end{array}$ & Rejected \\
H5 & $\begin{array}{l}\text { Job stress has a direct positive influence on job per- } \\
\text { formance. }\end{array}$ & Rejected \\
H6 & $\begin{array}{l}\text { Job stress has a direct positive influence on turnover } \\
\text { intention. }\end{array}$ & Accepted \\
\hline
\end{tabular}

\subsection{Practical Implications}

Results from the current study expand on previous research in diverse ways, all of which have managerial implications. Findings indicated that employees in the hospitality industry facing stressful working conditions are more likely to exhibit uncivil behaviors and increase turnover intention. Firstly, organizations must be aware of the harmful effects of stress in the workplace and develop policies aimed at reducing stressful working conditions. Professionals must also create opportunities for employees to learn effective ways to cope with stress. Furthermore, a job is another important factor affecting employees' turnover intention. As financial institutions merge and acquire, job stress has increased, especially for employees in the hotel industry in Ghana in recent years (Chen et al., 2011). Secondly, organizations can try to reduce the pressure on employees in the workplace by introducing a flextime time system. Workplace pressure should be proportional to employee capabilities and resources. The findings of the study also affirm that job content and demands, role conflict, and low salaries play a major role in causing stress among employees in the hospitality industry which had a negative influence on job performance because in jobs in Ghana is scarce employees will embrace the stress that comes with the job than to be jobless. Lastly, an emphasis should be placed on intervention at the organizational level to combat possible polite cases. Even if bosses and managers do their best to better understand and investigate workplace incivility, all efforts to combat workplace incivility will not work unless the right organization responds. Organizations need to ensure that their employees are not emotionally exhausted by the rude experience, as it has been found to alleImpact of Job Stress on Job Performance and Turnover Intention Among Employees in Hospitality Industry in Ghana 
viate emotional burnout between rude behavior in the workplace and the ability to perform their duties (Ferguson, 2012). One approach an organization can take is to help victims of ignorance in the workplace through free counseling and stress management training (Ferguson, 2012).

\subsection{Limitation and Future Research Prospect}

Although this study has many theoretical and practical implications, it is important to mention the limitations of our study. The main limitation is the nature of the non-probability sampling method (convenience sampling) used in the analysis. This fact means that we do not record longitudinal changes, so we must be very careful in determining the causal relationships between the variables. Studies involving longitudinal design will help overcome this limitation in future studies. Other mediators and dependent variables such as psychological capital, emotional intelligence, and job satisfaction were also not included in our study. These variables are important at the individual level in terms of emotional exhaustion and organizational outcomes, and these variables can further refine the model. Another limitation of this study is that the sample of employees was drawn from a specific industry in Ghana. The sample size and variety of the hospitality staff are very limited, so great care must be taken in summarizing it based on the results. Due to the limitations of our data, this study was not able to perform a longitudinal analysis that would allow us to further determine the causal relationships between the variables. Organizations in the hospitality industry can reduce employee stress by reducing employee workload, reducing role conflicts, and rethinking work to pay employees appropriately. In addition to this organizations should provide training to staff on learning stress management techniques to overcome stress issues to improve on job performance and turnover intention.

\section{Authors}

Dr. Kwame Asare Duffour holds a Ph.D. degree in Science of Business Administration from Zhejiang Gongshang University, China. He is also a graduate with a Master's degree in Business Administration specializing in International Business/Trade/Commerce from Zhejiang Normal University in Hangzhou, China. He has over 8 years' experience in business administration with diverse research experience in business and social research, particularly in the areas of social entrepreneurship, corporate social responsibility (CSR), organizational behavior and marketing. He has published articles in international journals like Culture and history, Resource and Environmental Economics, International Journal of Trends on Scientific Research and Development.

Patrick Kweku Gbolonyo is a recent Master of Science graduate from the School of Statistics and Mathematics, Zhejiang Gongshang University in China. He holds a Higher National Diploma (HND) in Statistics from the Takoradi Technical University, Ghana. Patrick Gbolonyo has over six years of experience in Statistics and Data Analysis. His research interest includes 
Economic Research, Market Research, Business Analysis, Big Data Analysis, E-commerce, Data Management, and Data Science.

Ting Chen has a Master's degree in Chinese and Foreign Policy from Anqing Formal University, Anqing, China. She also holds a Bachelor's degree majoring in International Business from Jingdezhen Ceramic University, Jingdezhen City, Jiangxi Province, China. She has a research interest in foreign policy direction, corporate entrepreneurship, organizational innovation, ethical decision-making, and organizational justice. Currently an office administration staff at the School of Business Administration, Zhejiang Gongshang University, Hangzhou, China.

\section{$7 \quad$ References}

Akgunduz, Y. (2014). The effect of organizational reliability of hotel employees on the preference of organizational silence. Journal of Organizational Management Science.

Alniaçik, E., Alniaçik, Ü., Erat, S., \& Akçin, K. (2013). Does Personorganization Fit Moderate the Effects of Affective Commitment and Job Satisfaction on Turnover Intentions? Procedia - Social and Behavioral Sciences, $\quad 99, \quad$ 274-281. https://doi.org/10.1016/i.sbspro.2013.10.495

Andersson, L., \& Pearson, C. (1999). Tit for Tat? The Spiraling Effect of Incivility in the Workplace. The Academy of Management Review, 24, 452-471. https://doi.org/10.2307/259136

Applebaum, D., Fowler, S., Fiedler, N., Osinubi, O., \& Robson, M. (2010). The impact of environmental factors on nursing stress, job satisfaction, and turnover intention. The Journal of Nursing Administration, 40(7-8), 323-328. https://doi.org/10.1097/NNA.0b013e3181e9393b

Arshadi, N., \& Damiri, H. (2013). The Relationship of Job Stress with Turnover Intention and Job Performance: Moderating Role of OBSE. ProImpact of Job Stress on Job Performance and Turnover Intention Among Employees in Hospitality Industry in Ghana 
cedia - Social and Behavioral Sciences, 84, 706-710. https://doi.org/10.1016/i.sbspro.2013.06.631

Bacharach, S. B., Bamberger, P. A., \& Sonnenstuhl, W. J. (2002). Driven to Drink: Managerial Control, Work-Related Risk Factors, and Employee Problem Drinking. The Academy of Management Journal, 45(4), 637-658. https://doi.org/10.2307/3069302

Bakker, A. B., \& Demerouti, E. (2007). The Job Demands-Resources model: State of the art. Journal of Managerial Psychology, 22(3), 309-328. https://doi.org/10.1108/02683940710733115

Barling, J., Kelloway, K., \& Frone, M. (2005). Handbook of Work Stress.

Brashear, T. G., Boles, J. S., Bellenger, D. N., \& Brooks, C. M. (2003). An empirical test of trust-building processes and outcomes in sales manager-salesperson relationships. Journal of the Academy of Mar-

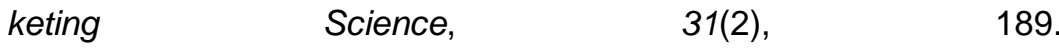
https://doi.org/10.1177/0092070302250902

Bruk-Lee, V., \& Spector, P. E. (2006). The social stressorscounterproductive work behaviors link: Are conflicts with supervisors and coworkers the same? Journal of Occupational Health Psychology, 11(2), 145-156. https://doi.org/10.1037/1076-8998.11.2.145

Carpini, J., Parker, S., \& Griffin, M. (2017). A Look Back and a Leap Forward: A Review and Synthesis of the Individual Work Performance Literature. The Academy of Management Annals, 11, 1-61. https://doi.org/10.5465/annals.2015.0151 
Cascio, W. (1984). Costing Human Resources: The Financial Impact of Behavior in Organizations / W.F. Cascio. The Academy of Management Review, 9. https://doi.org/10.2307/258455

Chen, M.-F., Lin, C.-P., \& Lien, G.-Y. (2010). Modeling job stress as a mediating role in predicting construction workers. Journal of Safety Research, 34(2).

Chen, M.-F., Lin, C.-P., \& Lien, G.-Y. (2011). Modelling job stress as a mediating role in predicting turnover intention. The Service Industries $\begin{array}{ll}\text { Journal, } & \text { 31(8), }\end{array}$ https://doi.org/10.1080/02642060903437543

Ciarocco, N., Vohs, K., \& Baumeister, R. (2010). Some Good News About Rumination: Task-Focused Thinking After Failure Facilitates Performance Improvement. Journal of Social and Clinical Psychology, 29, 1057-1073. https://doi.org/10.1521/jscp.2010.29.10.1057

Cohen, J. (1992). A power primer. Psychological Bulletin, 112(1), 155-159. https://doi.org/10.1037//0033-2909.112.1.155

Cortina, L., Magley, V., Williams, J., \& Langhout, R. (2001). Incivility in the Workplace: Incidence and Impact. Journal of Occupational Health Psychology, 6, 64-80. https://doi.org/10.1037/1076-8998.6.1.64

Fay, D., \& Sonnentag, S. (2002). Rethinking the effects of stressors: A longitudinal study on personal initiative. Journal of Occupational Health Psychology, 7, 221-234. https://doi.org/10.1037//1076-8998.7.3.221 
Ferguson, M. (2012). You cannot leave it at the office: Spillover and crossover of coworker incivility. Journal of Organizational Behavior, 33(4), 571-588. https://doi.org/10.1002/job.774

Firth, L., Mellor, D. J., Moore, K. A., \& Loquet, C. (2004). How can managers reduce employee intention to quit? Journal of Managerial Psychology, 19(2), 170-187. https://doi.org/10.1108/02683940410526127

Folkman, S., \& Lazarus, R. S. (1985). If it changes it must be a process: Study of emotion and coping during three stages of a college examination. Journal of Personality and Social Psychology, 48(1), 150170. https://doi.org/10.1037//0022-3514.48.1.150

Folkman, S., \& Moskowitz, J. T. (2004). Coping: Pitfalls and promise. Annual $\begin{array}{llll}\text { Review } & \text { of } & \text { Psychology, } & \text { 55, }\end{array}$ https://doi.org/10.1146/annurev.psych.55.090902.141456

Fornell, C., \& Larcker, D. F. (1981). Evaluating Structural Equation Models with Unobservable Variables and Measurement Error. Journal of Marketing Research, 18(1), 39-50. https://doi.org/10.2307/3151312

Foulk, T. A., Lanaj, K., Tu, M.-H., Erez, A., \& Archambeau, L. (2018). Heavy Is the Head that Wears the Crown: An Actor-centric Approach to Daily Psychological Power, Abusive Leader Behavior, and Perceived Incivility. Academy of Management Journal, 61(2), 661-684. https://doi.org/10.5465/ami.2015.1061

Foulk, T., Woolum, A., \& Erez, A. (2016). Catching rudeness is like catching a cold: The contagion effects of low-intensity negative behaviors. 
The Journal of Applied Psychology, 101(1), 50-67. https://doi.org/10.1037/apl0000037

Frijda, N. H. (1987). The Emotions. Cambridge University Press.

Griffin, M., \& Clark, C. M. (2014). Revisiting cognitive rehearsal as an intervention against incivility and lateral violence in nursing: 10 years later. Journal of Continuing Education in Nursing, 45(12), 535-542; quiz 543-544. https://doi.org/10.3928/00220124-20141122-02

Hair, J. F., Ringle, C. M., \& Sarstedt, M. (2011). PLS-SEM: Indeed a Silver Bullet. Journal of Marketing Theory and Practice, 19(2), 139-152. https://doi.org/10.2753/MTP1069-6679190202

Hansen, R. J. (1993). Personal harassment in the Canadian force: 1992 survey. Canadian Forces Personnel Applied Research Unit.

Henseler, J., Ringle, C. M., \& Sarstedt, M. (2015). A new criterion for assessing discriminant validity in variance-based structural equation modeling. Journal of the Academy of Marketing Science, 43(1), 115135. https://doi.org/10.1007/s11747-014-0403-8

Hobfoll, S. E. (2001). The Influence of Culture, Community, and the NestedSelf in the Stress Process: Advancing Conservation of Resources Theory. Applied Psychology, 50(3), 337-421. https://doi.org/10.1111/1464-0597.00062

Jackson, S., \& Schuler, R. (1985). A Meta-Analysis and Conceptual Critique of Research on Role Ambiguity and Role Conflict in Work Settings. Organizational Behavior and Human Decision Processes, 36, 1678. https://doi.org/10.1016/0749-5978(85)90020-2 
Jex, S. M. (1998). Stress and job performance: Theory, research, and implications for managerial practice (pp. xiv, 129). Sage Publications Ltd.

Koeske, G. F., \& Koeske, R. D. (1993). A Preliminary Test of a StressStrain-Outcome Model for Reconceptualizing the Burnout Phenomenon. Journal of Social Service Research, 17(3-4), 107-135. https://doi.org/10.1300/J079v17n03 06

Lau, V., Au, W., \& Ho, J. (2003). A Qualitative and Quantitative Review of Antecedents of Counterproductive Behavior in Organizations. Jour$\begin{array}{llll}\text { nal of Business and Psychology, } 18 . & \end{array}$ https://doi.org/10.1023/A:1025035004930

Lee, T. W., Mitchell, T. R., Sablynski, C. J., Burton, J. P., \& Holtom, B. C. (2004). The Effects of Job Embeddedness on Organizational Citizenship, Job Performance, Volitional Absences, and Voluntary Turnover. The Academy of Management Journal, 47(5), 711-722. https://doi.org/10.2307/20159613

Liao, H., \& Chuang, A. (2004). A Multilevel Investigation of Factors Influencing Employee Service Performance and Customer Outcomes. Academy of Management Journal, 47, 41-58. https://doi.org/10.5465/20159559

Maslach, C., \& Jackson, S. E. (1981). The measurement of experienced burnout. Journal of Organizational Behavior, 2(2), 99-113. https://doi.org/10.1002/job.4030020205

Netemeyer, R. G., Boles, J. S., McKee, D. O., \& McMurrian, R. (1997). An Investigation into the Antecedents of Organizational Citizenship BeImpact of Job Stress on Job Performance and Turnover Intention Among Employees in 
haviors in a Personal Selling Context. Journal of Marketing, 61(3), 85-98. https://doi.org/10.2307/1251791

Neveu, J.-P. (2007). Jailed resources: Conservation of resources theory as applied to burnout among prison guards. https://doi.org/10.1002/JOB.393

Nicholson, T., \& Griffin, B. (2014). Here Today but Not Gone Tomorrow: Incivility Affects After-Work and Next-Day Recovery. Journal of Occupational Health Psychology, 20. https://doi.org/10.1037/a0038376

Nunnally, J. C., \& Bernstein, I. H. (1994). Psychometric theory. McGraw-Hill.

Pearson, C. M., \& Porath, C. L. (2005). On the nature, consequences and remedies of workplace incivility: No time for "nice"? Think again. Academy of Management Perspectives, 19(1), 7-18. https://doi.org/10.5465/ame.2005.15841946

Penney, L. M., \& Spector, P. E. (2005). Job stress, incivility, and counterproductive work behavior (CWB): The moderating role of negative affectivity. Journal of Organizational Behavior, 26(7), 777-796. https://doi.org/10.1002/job.336

Porath, C. L., \& Erez, A. (2007). Does Rudeness Really Matter? The Effects of Rudeness on Task Performance and Helpfulness. Academy of $\begin{array}{lll}\text { Management } \quad \text { Journal, } & \text { 50(5), } & \text { 1181-1197. }\end{array}$ https://doi.org/10.5465/ami.2007.20159919

Porath, C. L., Overbeck, J. R., \& Pearson, C. M. (2008). Picking up the gauntlet: How individuals respond to status challenges. Journal of 
Applied Social Psychology, 38(7), 1945-1980. https://doi.org/10.1111/j.1559-1816.2008.00375.x

Sakurai, K., \& Jex, S. M. (2012). Coworker incivility and incivility targets' work effort and counterproductive work behaviors: The moderating role of supervisor social support. Journal of Occupational Health Psychology, 17(2), 150-161. https://doi.org/10.1037/a0027350

Saroj, N., \& Nazia, M. (2009). Examining the Relationship between Work Life Conflict, Stress and Turnover Intentions among Marketing Executives in Pakistan. International Journal of Business and Management, 3. https://doi.org/10.5539/ijbm.v3n11p93

Sawyerr, O., Srinivas, S., \& Wang, S. (2009). Call center employee personality factors and service performance. Journal of Services Marketing $\begin{array}{llll}\text { - J SERV MARK, 301-317. } & \text { 23, }\end{array}$ https://doi.org/10.1108/08876040910973413

Settles, I. H., Sellers, R. M., \& Damas, A. (2002). One role or two?: The function of psychological separation in role conflict. Journal of Applied Psychology, 87(3), 574-582. https://doi.org/10.1037/0021$\underline{9010.87 .3 .574}$

Shaw, J. D., Duffy, M. K., Johnson, J. L., \& Lockhart, D. E. (2005). Turnover, Social Capital Losses, and Performance. The Academy of Management Journal, 48(4), 594-606. https://doi.org/10.2307/20159681

Sheridan, J. E. (1992). Organizational Culture and Employee Retention. Academy of Management Journal, 35(5), 1036-1056. https://doi.org/10.5465/256539 Impact of Job Stress on Job Performance and Turnover Intention Among Employees in Hospitality Industry in Ghana 
Shih-Tse Wang, E. (2014). The effects of relationship bonds on emotional exhaustion and turnover intentions in frontline employees. Journal of Services Marketing, 28(4), 319-330. https://doi.org/10.1108/JSM-11$\underline{2012-0217}$

Simon, H. A. (1967). Motivational and emotional controls of cognition. Psychological Review, 74(1), 29-39. https://doi.org/10.1037/h0024127

Siu, O., Phillips, D. R., \& Leung, T. (2003). Age differences in safety attitudes and safety performance in Hong Kong construction workers. Journal of Safety Research, 34(2), 199-205. https://doi.org/10.1016/s0022-4375(02)00072-5

Smith, C. A., Tong, E. M. W., \& Ellsworth, P. C. (2014). The differentiation of positive emotional experience as viewed through the lens of appraisal theory. In Handbook of positive emotions (pp. 11-27). The Guilford Press.

Smith, P. C., \& Goddard, M. (2002). Performance management and Operational Research: A marriage made in heaven? Journal of the Operational Research Society, 53(3), 247-255. https://doi.org/10.1057/palgrave.jors.2601279

Starr, M., Saarsalmi, A., Hokkanen, T., Merilä, P., \& Helmisaari, H.-S. (2005). Models of litterfall production for Scots pine (Pinus sylvestris L.) in Finland using stand, site and climate factors. Forest Ecology and Management, 205, 215-225. https://doi.org/10.1016/i.foreco.2004.10.047 
Tett, R. P., \& Meyer, J. P. (1993). Job Satisfaction, Organizational Commitment, Turnover Intention, and Turnover: Path Analyses Based on Meta-Analytic Findings. Personnel Psychology, 46(2), 259-293. https://doi.org/10.1111/j.1744-6570.1993.tb00874.x

Van Yperen, N., \& Hagedoorn, M. (2003). Do high job demands increase intrinsic motivation or job strain or both? The role of job control and social support. The Academy of Management Journal, 46, 339-348. https://doi.org/10.2307/30040627

Weiss, H., \& Cropanzano, R. (1996). Affective Events Theory: A Theoretical Discussion of The Structure, Cause and Consequences of Affective Experiences at Work. Research in Organizational Behavior. 